\title{
WHY WE NEED TO TALK ABOUT TEAMS AND COMMUNICATION IN PALLIATIVE CARE
}

\section{Introduction}

Palliative care is one of the fastest growing areas of medicine. This vital field focuses on the care of seriously ill patients and their families. Team-based care has proven to be very effective in palliative care, and hospitals and health systems are turning toward this practice in ever greater numbers. However, many palliative care providers-physicians, APRNs, registered nurses, social workers, chaplains, and pharmacists-have limited experience working on a sustained, daily basis with colleagues outside of their discipline. When a team struggles to work together well, that stress compounds the already stressful environment that surrounds the care of the seriously ill. That compounded stress can lead to team turnover as members leave for other areas of practice or leave the field altogether. Given the importance of palliative care to families and to healthcare systems and hospitals, it is imperative that we find a way to help teams survive and thrive. Although often overlooked, a focus on interpersonal, team, and organizational communication can set a solid foundation on which teams can do just that-thrive as a team while doing the important work of caring for patients and families.

\section{Negative Palliative Care Experience}

Physician Experience: On a weekly basis, I'll have other physicians cut in line in the doctor's dining room and make remarks like "It's not like you need to rush to save anyone" or "It must be nice not to have to deal with an OR schedule." There's one guy in particular, a cardiologist, who will not only cut in front of me and then intentionally take as much time as is humanly possible to make a salad, but he'll also take

A podcast to accompany this chapter is available with online access of this title. Please see the instructions on the first page of the book for details on how to access and go to Chapter 1. 
the newspaper right out of my hands and say "It's amazing you don't have this on 6 [location of the palliative care unit]. I don't know what you do with all of that time when you're babysitting the dying."

\section{Positive Palliative Care Experience}

Physician Experience: This is the best team I've ever worked on. I mean, they're phenomenal. I think the other thing that really makes this work in a very positive way [is something] that maybe some other teams [at the hospital] have trouble connecting is that this is really meaningful work. And sometimes you may lose sight of the impact that has on team satisfaction; then you see one of your colleagues really do some amazing things with the family, and you see the outcome of that. You realize that you made a difference. You get to feel that and experience that. Every time I'm on this [palliative care team] service that happens. I can't say that happens on every team I'm on. Those are things that offset the draining portion of it [palliative care]. It's recognizing "This was heading down a path that could have been really bad, and we made a difference." It's very emotionally engaging, and you feel drained sometimes, but there is also this filling of the well again by your colleagues as well as just the meaning of the work.

\section{The Growth Trajectory of Palliative Care}

The Center to Advance Palliative Care (CAPC) estimates that 12 million adults and 400,000 children in the United States are living with a serious disease, and that number is expected to double in the next 25 years (CAPC, 2018). Palliative care is specialized medical care for people with serious illnesses that is focused on the relief of symptoms, pain, and stress of a serious illness-whatever the stage of disease. In a best-practice scenario, this type of care is provided by an interdisciplinary team, usually comprised of physicians, nurses, social workers, and chaplains (CAPC, 2019b). Unlike hospice, which is end-of-life care for terminally ill patients, palliative care requires no enrollment or benefit choice and can be provided concurrently with curative treatment (National Consensus Project Clinical Practice Guidelines for Quality Palliative Care [NCP Guidelines], 2018; World Health Organization [WHO], 2017). The development of hospital-based palliative care services has been one of the most rapidly growing trends in the past 15 years as, in addition to the improvement of patient and family care, good palliative care teams (PCTs) provide cost savings to their hospitals (McCarthy, Robinson, Huq, Philastre, \& Fine, 2015). CAPC, founded in 1999, continues to see growth in membership and conference participation (Meier, 2019 podcast). Thus, even though "payment cuts for the chronically ill and elderly are increasing” (Candrian, 2015, p. 732), palliative care development and utilization in hospitals is likely to continue its current trajectory. 


\section{Why Focus on Teams and Communication in Palliative Care?}

In Clinical Practice Guidelines for Quality Palliative Care, Fourth Edition (NCP, 2018), the first section of the best-practice guidelines is devoted to the necessity of quality interdisciplinary teams. The list is comprehensive and mentions team communication numerous times. While it is not uncommon to see "good communication" listed as an important component of great healthcare, it is uncommon for that standard to be followed with research and ideas on how to recognize, teach, and perform good interpersonal, team, and organizational communication in healthcare settings. This book is the resource to help organizations form and/or maintain high-performing PCTs that can meet these guidelines. Combining the research on palliative care, high-performing teams, and healthcare organizational culture, this book uses original data sets, peer-reviewed literature, and national data banks to help you form a PCT or to transform your current team into one with less turnover. This book can help you to mindfully create a new PCT or enhance an already formed PCT in a way that relies on teamwork to help team members thrive in the sometimes difficult world of palliative care.

While teams are a newer way of organizing in many areas of healthcare, they are becoming the standard for palliative care. PCTs model holistic care through assembling multiple disciplines to work together to care for patients and families. Teams are important in palliative care, as teams gather the necessary resources of the disciplines of physicians, nurses, social workers, chaplains, and pharmacists to offer the best possible patient care. In addition, a wellfunctioning team has the added benefit of making better decisions and avoiding member burnout.

It is likely that you work in palliative care because you believe that providing excellent palliative care is essential to the well-being of patients, families, and healthcare systems. In health systems where the focus has long been on curing and ideas of a good death have often been framed as "giving up," palliative care providers fulfill the ethical and moral obligation to care for patients and families experiencing serious illness regardless of the possibility of curing that illness. Given the swift rise of palliative care in hospital systems, this book considers three truths in palliative care:

1. The demand for palliative care continues to grow.

2. The challenge of delivering excellent palliative care is best met through interdisciplinary teams.

3. Teams function best when they make intentional communication a priority. 


\section{Palliative Care Truth No. 1: Increasing Demand for Palliative Care}

As palliative care continues its meteoric rise, devoting time, energy, and money to developing high-performing PCTs is a worthwhile investment. The palliative care subspecialty holds a unique role in the illness trajectory in that it focuses entirely on the relief of suffering and improvement of quality of life within the context of a serious illness. Recognition that palliative care results in improved quality of care and reduced cost has led to health systems' investment in the development of palliative care programs. Access to palliative care for seriously ill patients and their families is increasingly recognized as a clinical and moral imperative (Institute of Medicine [IOM], 2014). With professional guidelines such as those by the American Society of Clinical Oncology (ASCO) and disease-specific accreditation programs requiring early and routine concurrent palliative care, it has become increasingly clear that the need for palliative care will continue to outpace access to specialty palliative care clinicians (Compton-Phillips \& Mohta, 2019; Quill \& Abernathy, 2013).

As healthcare systems work to meet the complex needs of seriously ill patients with the recognition of an impending workforce shortage of specialty-trained palliative care providers (Kamal et al., 2017), there is an increasingly urgent call to promote primary palliative care, which is delivered by healthcare professionalsnot palliative care specialists-such as primary care and disease-oriented clinicians (e.g., oncologists and cardiologists) as well as nurses, social workers, pharmacists, chaplains, and others who care for seriously ill patients and their families but are not specialty trained in palliative care (IOM, 2014).

According to Quill and Abernathy (2013), primary palliative care includes basic competency in:

- Pain and symptom management

- Depression and anxiety management

- Communication about prognosis, goals of treatment, suffering, and advance care planning

Specialty palliative care, provided by skilled and highly trained professionals, is required for the management of:

- Refractory pain and symptoms

- Complex depression, anxiety, grief, and existential distress

- Conflict resolution within families, between families and the treating teams, and among treatment teams

- Assistance with cases of medical futility 
While the roles between providers of primary- and specialty-level palliative care will inevitably blur at times, the need for highly trained, dedicated PCTs to address the complex care needs of seriously ill patients and their families will remain paramount. In addition to providing direct care, specialty-level palliative care providers are also called upon to transform serious illness care through mentorship and training of all care providers on basic pain and symptom management and communication skills (i.e., CAPC Tipping Point Challenge, 2019). This quickly growing area of clinical care is here to stay. Given that a 2019 report on the results of the Catalyst Insights Council survey found that while "the great majority of organizations have a palliative or end-of-life care program, $60 \%$ of patients who would benefit from such services don't receive them" (Compton-Phillips \& Mohta, 2019), the rate of growth in palliative care has not yet met the need. Additionally, the demand for palliative care will only continue to grow due to aging populations and improved clinical outcomes for seriously ill patients.

\section{Aging Population}

In 2030, the last of the baby boomers will turn 65. The U.S. Census Bureau predicts that by 2035, the number of people over 65 will outnumber the number of children under 18 for the first time in the history of the United States. As those over 65 use health services at much higher rates (e.g., May et al., 2018) than the rest of the population, the demand for palliative care professionals will rise. The public will demand the services and hospitals will look to PCTs to help keep expenditures under control. Approximately half of palliative care use is from patients between the ages of 65 and 85 (National Palliative Care Registry, 2017). Many members of this aging population have one or more chronic diseases. According to the Centers for Disease Control and Prevention (CDC, 2019), 60\% of adults in the United States have one chronic disease, and $42 \%$ of U.S. adults have two or more. The leading chronic diseases in U.S. adults include the following:

- Heart disease

- Cancer

- Chronic lung disease

- Stroke

- Alzheimer's disease

- Diabetes

- Chronic kidney disease

These diseases are the leading causes of death and disability in the United States and are the primary drivers of the nation's $\$ 3.3$ billion in annual healthcare costs. Among 
those aged 65 to 85 , the population with the highest use of palliative care, two thirds of patients have multiple chronic conditions. So what does this mean for palliative care? It means that the medical specialty is likely to continue growing at exponential rates, and that, in turn, means that individual providers, teams, and organizations need to be equipped to offer patient-centered care in the face of the increased demand.

\section{Improved Clinical Outcomes}

The growing use of palliative care in the United States points to a sizable shift in Western medicine-an understanding that the quality of a patient's life is at least as important as the number of years a patient lives. Considerable evidence (Box 1.1) exists showing that palliative care improves clinical outcomes throughout the trajectory of serious illness care.

\section{BOX 1.1}

\section{EVIDENCE FOR IMPROVED OUTCOMES WITH PALLIATIVE CARE}

Davis et al. (2015)

A meta-analysis of outpatient and home palliative care studies found that despite some methodological concerns, the current state of palliative care research supports the conclusion that early outpatient and home palliative care may improve the patient's quality of life.

\section{Fitzpatrick et al. (2018)}

"Early intervention with inpatient palliative care consultation (within 3 days) correlated with financial benefit as well as earlier referral to more appropriate levels of care" (CAPC-Research in the field, 2019a).

\section{Kerr et al. (2014)}

Among patients with life-limiting or serious illness enrolled in a blended outpatient/ home palliative care program, symptomology improved in six domains: anxiety, appetite, dyspnea, well-being, depression, and nausea.

\section{Kavalieratos et al. (2016)}

A meta-analysis found that palliative care was associated with statistically and clinically significant improvements in both patient quality of life (QOL) and symptom burden at the 1- to 3-month follow-up. Additionally, palliative care was associated consistently with improvements in advance care planning, patient and caregiver satisfaction, and lower healthcare utilization. 
See the Center to Advance Palliative Care's (CAPC) website on Research in the Field (https://registry.capc.org/metrics-resources/research-in-the-field) for more article suggestions to help make your case for starting, growing, and maintaining palliative care teams in your organization.

\section{BOX 1.2}

\section{A PHYSICIAN REFLECTS: PALLIATIVE CARE IS DESERVING OF HOSPITAL RESOURCES}

A colleague from neurology approached me in a highly agitated state after he found out that my palliative group received permission for new hires and promotional materials. He could not come to grips with this. He could not rationalize why the organization would give money to a program that was not revenue generating. The problem with this is that making money is prized over ethical obligation. I didn't become a doctor to make an organization rich. I went into palliative care because caring for people is the right thing to do (Omilion-Hodges \& Swords, 2017).

A recent nuance of that shift is that the quality of a patient's death is also important (Box 1.2). Evidence of this shift includes the creation of numerous assessment measures, which were systematically studied by Hales, Zimmerman, and Rubin (2010). They found the Quality of Death and Dying Scale (QODD) to be the most used and best validated. One consideration for this measure is that it is used retrospectively for the family to consider the last days of the loved one's life. In other words, when families are in the midst of dealing with serious illness, they do not necessarily make the decisions that they will later wish they had made. Physician and author Atul Gawande reflects on this with the spouse of a former patient in the PBS Frontline episode, Being Mortal (Jennings, 2015). As Boston surgeon Dr. Gawande notes, due to the patient and family focus on treatment, he held back from encouraging them to focus on the time the patient had remaining. The patient's husband now also speaks of their hyperfocus on treatment and how he wishes they would have chosen a palliative path earlier and enjoyed more of her ending days together.

\section{Growth of PCTs}

Given the evidence of need for specialized seriously ill care and the possibilities of significant fiscal savings for hospitals and health systems, the number of PCTs 
is increasing in clinical practice. J. Andrew Billings issued a call to arms in 2002, stating, "Our focus for the moment should be in developing skilled interdisciplinary teams that provide high-quality, coordinated care across settings" (p. 298). Many healthcare systems are working to answer that call. Nearly $90 \%$ of hospitals with 300 or more beds (Dumanovsky et al., 2016) and 79\% of hospitals with 50 or more beds (CAPC, 2018) have specialty palliative care programs. At least 1,852 sites of service in the United States offer specialized palliative care (CAPC, 2018). While this is encouraging, very few of these hospitals have sufficient staffing for their programs (Spetz et al., 2016). Ledford, Canzona, Cafferty, and Kalish (2016) also point out that the majority of palliative care is offered by internists without specific palliative care training or the support of a PCT. So while programs are growing, the training of experts in palliative care is not keeping pace. The 2014 IOM report, Dying in America, found "inadequate numbers of palliative care specialists and too little palliative care knowledge among other clinicians who care for individuals with serious advanced illness" (p. 2). With just 3\% of U.S. hospitals holding certification in specialized palliative care (CAPC, 2018), the growth and training opportunities for PCTs are numerous.

\section{(D) Palliative Care Truth No. 2: The Challenge of Providing Excellent Palliative Care is Best Met through Interdisciplinary Teams}

The team model harnesses the expertise of multiple disciplines into a single care team. These teams benefit from the perspectives of the different disciplines and, if they manage to form a high-performing team, can develop a model of learning and shared care among team members that benefits both the team and the patients and families with whom the team works. Some teams form a minimally competent model, and while they work together, they do not work together particularly well. Table 1.1 delineates the minimally performing team from the high-performing team. This chart illustrates how an idea that sounds simple is often very difficult to construct-how do you form a great team? This book will assist you with the answer to that question.

\section{Fiscal Savings for Hospitals}

While it is better for care providers to have a high-performing team, why should hospitals and healthcare systems be motivated to invest in helping to create high-performing teams rather than remaining satisfied with minimally performing teams? If palliative care models were not financially beneficial for hospitals, it 


\section{TABLE 1.1 Minimally Versus High-Performing Palliative Care Teams (PCTs)}

\begin{tabular}{|l|l|}
\hline HIGH-PERFORMING PCTS & MINIMALLY PERFORMING PCTS \\
\hline $\begin{array}{l}\text { Proactive process to identity patients } \\
\text { appropriate for PCT referrals }\end{array}$ & $\begin{array}{l}\text { Reactive patient identification process } \\
\text { for PCT involvement }\end{array}$ \\
\hline $\begin{array}{l}\text { Flexible approaches to pain } \\
\text { management }\end{array}$ & $\begin{array}{l}\text { Standardized approach to pain } \\
\text { management }\end{array}$ \\
\hline $\begin{array}{l}\text { Clear roles and responsibilities of } \\
\text { team members }\end{array}$ & $\begin{array}{l}\text { Confusing roles and unclear } \\
\text { responsibilities for team members }\end{array}$ \\
\hline $\begin{array}{l}\text { High patient and family engagement } \\
\text { possible early in the disease process }\end{array}$ & $\begin{array}{l}\text { Burdensome time and resource } \\
\text { pressures due to late and limited } \\
\text { engagement with family and patient }\end{array}$ \\
\hline $\begin{array}{l}\text { Good understanding of PCT in the } \\
\text { context of the hospital organization }\end{array}$ & $\begin{array}{l}\text { Limited understanding of how the PCT } \\
\text { fits in the hospital context }\end{array}$ \\
\hline Great teamwork between experts & Experts who work together \\
\hline
\end{tabular}

SOURCE: Adapted from Hackett, J., Ziegler, L., Godfrey, M., Foy, R., \& Bennett, M. I. (2018). Primary palliative care team perspectives on coordinating and managing people with advanced cancer in the community: A qualitative study. BMC Family Practice, 19, 177. doi:10.1186/s12875-018-0861-z; Imes, R. S., \& Hester, J. (2015). Unintended intentional community at work: Applying a new lens to guide the formation and maintenance of transdisciplinary teams. Paper presented at the National Communication Association Annual Convention, Las Vegas; Omilion-Hodges, L. M., \& Baker, C. R. (2017). Communicating leader-member relationship quality: The development of leader communication exchange scales to measure relationship building and maintenance through the exchange of communication-based goods. International Journal of Business Communication, 54(2), 115-145. doi: $10.1177 / 2329488416687052$

is unlikely that the model would have survived, yet the number of hospitals with palliative care and patients utilizing palliative care services continues to surge. Palliative care can be a difficult concept for some medical specialties to understand because PCTs do not make money for the hospital; PCTs save money for the hospital (Box 1.3). These fiscal savings are another kind of value work provided by palliative care-the human value of caring for seriously ill people and economic value of saving hospitals' money through lower use of EDs and ICUs for palliative patients. While the humanity element is often cited by palliative care advocates as the primary argument for supporting PCTs in hospitals, fiscal savings for hospitals and systems make another compelling argument for building and supporting PCTs (Box 1.4). In fact, one source predicts that increased use of palliative care will save the U.S. healthcare system over $\$ 103$ billion before 2040 (Parker, 2019).

Mounting evidence shows that interdisciplinary PCTs save hospitals more money than those that have palliative care through a single discipline. For 


\section{BOX 1.3}

\section{STUDIES SHOW FISCAL SAVINGS FOR HOSPITALS WITH PALLIATIVE CARE}

\section{May et al. (2017)}

This study found that palliative care does save money over usual care.

- Three primary drivers of savings are lower room and board costs and fewer imaging and laboratory tests. In the United States, $63 \%$ of the savings came from lower room and board and 37\% from "reduced intensity of service" (p. 382).

- Pharmacy costs (the other high driver of costs in hospitals) were unchanged between usual care and palliative-involved care.

- Early palliative care involvement is a good predictor of savings. This study found a predictable correlation between late palliative care involvement and higher length of stay (LOS) and intensity of service costs.

\section{Meier et al. (2017)}

Palliative care in general can reduce healthcare costs by more than $\$ 4,000$ per patient. It can also reduce the frequency of 911 calls, ED visits, and unnecessary hospitalizations.

May et al. (2018)

In the specific case of oncology there was a reduction in cost of care with early palliative care involvement for diagnoses of primary cancer with comorbidities. Of those cases, the greatest reduction was found when a palliative care consultation occurred within three days of hospital admission for patients with a primary cancer and four or more comorbidities (p. 827).

\section{Smith et al. (2012)}

Kaiser Permanente, an insurer and provider of medical care for over 12 million members (https://share.kaiserpermanente.org/about-us/about-kaiser-permanente), designed palliative care standards in all areas for which Kaiser Permanente has a significant market share. The adoption was based on a randomized controlled trial that demonstrated savings of $\$ 5,000$ to $\$ 7,000$ per person.

example, a study of two similar Ohio hospitals within the same health system found that a PCT with physicians and APRNs resulted in earlier referrals and shorter lengths of stay, which resulted in greater cost savings for the hospital than the APRN-only team (Kousaie \& von Gunten, 2017, p. 1313). The authors attribute the difference in lengths of stay to the difference in communication between 


\section{BOX 1.4}

\section{A PHYSICIAN REFLECTS: RETURN ON INVESTMENT}

Our APRN has done a wonderful job putting the data together showing the administration what exactly they've put their money into, and now the administration understands. They truly bought into our plan, and when we ask for more, they can see the data. It's not just because we think we need it—we can prove to them the return on investment.

nurses and physicians depending on whether they were part of the same team. When they were not, the communication was characterized as indirect, and the authors discovered that the nurses were less likely to challenge the physician concerning the plan of care. When nurses and physicians were on the same PCT, the communication appeared more direct with all parties contributing to the conversation and adapting the plan. The authors identify this more direct, engaged team communication as the reason for the shortened post-consult lengths of stay, which was half that of the nurse-only team.

In addition to better team discussions, a fully staffed team can help avoid one of the pitfalls of palliative care-burnout. For example, a fully staffed team can make time for team members to do some of what helps them thrive in palliative care. In an underresourced team, the problem is compounded when staff burns out from, for example, only doing discharge planning. Now the team is down a person and trying to hire. If the team changes nothing, they know that the situation is likely to come up again. While changes in staffing models requiring new ways to think about billing may be difficult conversations to begin for health organizations, the data support interdisciplinary models. A good prediction tool can help the argument for a PCT. The CAPC provides a financial calculator on their website (https://www.capc.org/impact-calculator). See an example of one hospital's use of the impact calculator (Exhibit 1.1). This tool can assist teams in making hiring arguments to their administrators.

Scharf, Geist Martin, Cosgriff-Hernandez, and Moore (2012) study integrative medicine, which is another area of medicine that requires an expanded way of thinking about personnel organizing and billing. They remind us that "trailblazing integrative medicine includes a multitude of challenges that require novel ways of thinking" (p. 438). As the data show, teams are an excellent way to care for seriously ill patients while saving hospitals money. This indicates that the work that is necessary to create new structures is worth the effort. 


\section{EXHIBIT 1.1}

\section{CENTER TO ADVANCE PALLIATIVE CARE IMPACT CALCULATOR}

Estimated Financial Impact: An Example of Direct Cost Savings Based on One Hospital's Data

\begin{tabular}{|l|l|}
\hline DESCRIPTION & EXAMPLE* \\
\hline Estimated Average Cost per FTE Including Benefits With IDT Mix & $\$ 160,000$ \\
\hline Estimated Team Costs (Staffing FTE x Average Cost) & $\$ 1,184,000$ \\
\hline $\begin{array}{l}\text { Estimated Billing Revenue (Part B Professional at CMS 2017 } \\
\text { Rates }\end{array}$ & $\$ 509,290$ \\
\hline $\begin{array}{l}\text { Net Investment or Subsidy Needed (Staffing Costs- Billing } \\
\text { Revenue) }\end{array}$ & $\$ 674,710$ \\
\hline Estimated Direct Cost Savings per Case (Episode of Care) & $\$ 3,274$ \\
\hline Expected Cost Savings Before Deducting Net Investment & $\$ 4,953,562$ \\
\hline Expected Annual Direct Cost Savings (Savings - Investments) & $\$ 4,278,852$ \\
\hline
\end{tabular}

*Example data drawn from a large teaching hospital.

CMS, Centers for Medicare \& Medicaid Services; FTE, full-time equivalent; IDT, interdisciplinary team.

SOURCE: Center to Advance Palliative Care. CAPC impact calculator. Retrieved from https:// www.capc.org/impact-calculator/

\section{Palliative Care Truth No. 3: Teams Function Best When They Make Intentional Communication a Priority}

Palliative care is really hard work. Working with seriously ill patients and families with complex problems in a complex system can be draining. PCT colleagues Atayee and Edmonds (2018) remind us that labeling something as hard work is often frowned upon in the medical and pharmacy fields because "then it means we are complaining and don't care about our patients ... but the fact is that doing good palliative care is hard ... more than this, working as a team is hard" (p. 1386). Difficulties in providing palliative care on PCTs include the following:

- Caring for patients with serious illness

- Assisting families of patients with serious illness 
Dealing with grief as a provider

- Working in a culture of healthcare that may stigmatize palliative care as "giving up"

- Relating to team members with different personalities, from different disciplines, and with different underlying assumptions of how groups work together

- Embedding teams in hospital environments that have long worked under organizational structures of separation rather than interdisciplinary models

Given all these challenges, it may seem easier to forget about the team aspects and simply focus on patient care. However, the data show that interdisciplinary models are the best way to provide efficacious palliative care. Thus, focusing on the team must be a priority, and focusing on the team means focusing on communication. Watson, Heatley, Gallois, and Kruske (2016) found that "communication is perceived to be pivotal to collaborative practice. Nonetheless, the abilities and perceptions of care providers about communication can create difficulty in the application of collaborative practice" (p. 405). Klarare et al. elaborate on the importance of collaboration for the self-worth of individual collaborators, saying "that is crucial. No one wants to feel that 'I am replaceable' and that nothing changes even if I disappear....You need to feel that it is good that you are here, because you bring us closer to our goal" (2013, p. 1066). With a strong focus on intentional communication for team building and maintenance, the hard work of caring for seriously ill patients and their families is less likely to be compounded by collaborative communication issues. When teams make communication a priority, even times of conflict are resolved faster and have few, if any, negative outcomes for the team environment.

To build PCTs that survive and thrive, a deep understanding of team and organizational communication is required. In fact, professional communication skills for healthcare providers is a topic that gets more attention with each passing year. In 2013, the Health Professionals Core Communication Curriculum (HPCCC) published their consensus learning objectives for medical education in Europe (Bachmann et al., 2013). In addition to an extensive section on provider-patient communication, the report includes a section devoted to communication on healthcare teams with subsections of teamwork and professional communication, leadership, and professional communication and management.

In the United States, similar communication deficits are noted. Nussbaum and Fisher (2009) define communicatively competent people as "individuals whose skills enable him or her to adapt to the challenges of the situation and, thus, have a better chance of completing a productive and satisfying interaction" (p. 199). Unfortunately, advanced communication skills were the most reported 
skill lacking among the people hired by community-based palliative care leaders (Dudley, Chapman, \& Spetz, 2018). A 2018 study by Fulmer et al. found that only $29 \%$ of physicians reported formal training in how to conduct end-of-life conversations and $46 \%$ of the sample reported feelings of uncertainty about what to say in such conversations. Without adept communication, it becomes more challenging for providers to manage the emotional labor associated with the profession in addition to successfully navigating team conflict, status struggles, or successfully arguing for additional organizational resources. To better navigate these tensions, a good understanding of the foundational role of communication in relationships and workplace environments is necessary.

\section{Foundational Role of Communication}

Communication is often acknowledged as vital for teams and interpersonal interactions and yet is also often described in simplistic terms of how information is transmitted. Given all of the struggles that involve communication, it is useful to think of the foundational nature of communication as meaning making. A lingering misconception about communication is that it is simply a tool to pull out when someone would like to (a) get his or her way or (b) use it to clarify misunderstandings. This is a very simplistic view of communication. Focusing on communication as transmission can clear up misunderstandings if someone simply did not hear the other person correctly. In those situations, repeating or choosing a different channel of communication (i.e., avoiding texting when emotional nuance is a part of the message) can clear up the misunderstanding. However, when organizations cite "communication problems," the issue is usually one of meaning making between two or more people. In those situations, the preceding solutions do not work. If there is a value disagreement at the heart of a conflict, simply restating it louder and more slowly will not solve the conflict. For example:

- "I don't want to hire more people in palliative because palliative is about quitting. It's about giving up, and I don't want our patients to think we would give up on them! So we should use the funds to hire another APRN for my department because we are involved in actually curing patients."

- "'Just' a nurse?! Did you hear him say that I'm 'just' a nurse? I'm the one who caught three big medical mistakes last year!"

A more sophisticated view is to consider communication as a foundation. Without a solid foundation, homes sustain structural damage and cannot provide shelter. Without a solid foundation, marriages and relationships tend to 
crumble under everyday pressures and stressors. Neither of the preceding examples is simply a situation of not hearing someone correctly. Both show a difference in value and a difference in cultural communication expectation. Restating the same claim will not resolve these differences-both parties need to collaboratively communicate to try and get on the same page. Even with great communication, they may not agree, but they will better understand the other person's point of view.

Viewing communication as foundational suggests that it becomes the predominate lens for navigating and facilitating relationships, delivery of patient care, and traversing organizational life.

\section{What the Foundational Role of Communication Looks Like in the Healthcare Environment}

Intentional language usage: Often, we are not fully aware of how our word choices may impact others. One of the authors worked on a healthcare team where her manager would refer to the team as "just my staff" and the administrative assistant as "just a secretary." The manager would most commonly do this when she was interacting with peers at her level or with organizational members at higher levels. Yet, when the manager communicated with the team without any higher status members present, she would call them her "dream team" and her "rock stars." No one, at any level, would ever like to be referred to as just a (nurse/social worker/chaplain/physician).

Additionally, the use of pejorative terms, such as staff instead of team and secretary instead of the more commonly used administrative assistant, can also put undue stress on individuals and negatively impact team leadmember relationships and team dynamics. The moral of the story is that language is powerful and can be used inclusively to fortify relationships or can inadvertently (or worse yet, intentionally) be used to stress status and power distinctions. The latter has resulted in a long history of medical errors and mishaps because exclusive language that stresses power differences and hierarchies can result in reduced interaction or the absence of communication (Lingard, Whyte, \& Regehr, 2009; Makary \& Daniel, 2016; Sutcliffe, Lewton, \& Rosenthal, 2004).

- Active listening: The concept of active listening is quite simple-being present and engaged while listening to another. This may be in a hallway conversation with a peer, in a team meeting, or when engaging with a patient. Though it is easy to grasp theoretically, active listening requires practice, discipline, and trust. It may be easy to see how learning to remain in the present moment can take discipline and practice as we learn how to quiet our own 
thoughts as we fully consider the setting or context, the other individual's needs or goals, and our role in the situation (Omilion-Hodges \& Swords, 2017). However, the role of trust may not be as obvious. When we engage in active listening in order to be present and to suspend our own desires and goals, we need to trust that others will return the favor. This is especially challenging in moments of conflict, if we are angry, fearful, or upset. In these moments, it is much easier to appear as though we are listening and instead silently work on our own rebuttal. Yet, doing so does not allow us to hear the other's perspective or point of view and, therefore, may result in a missed opportunity for understanding.

Active listening also includes asking questions, paraphrasing, and demonstrating affirming body language. Asking questions indicates that we have been attentive, whereas paraphrasing allows us to verify that we have interpreted or understood the other's perspective. Affirming body language includes making eye contact, facing the other person with open posture (uncrossing arms, leaning in to the speaker, and ignoring distractions), and nodding. This can be especially challenging in the fast-paced healthcare environment where phones, alarms, and hallway chatter create consistent background noise.

- Other-oriented approach: This foundational communication tactic means a sincere attempt to understand before trying to be understood. An other-oriented approach also involves empathy in addition to intentional language usage and active listening. Especially in situations that involve disagreements or are riddled with pressure (a patient crashing), it can feel as though the only way to address or resolve the situation is by shouting our needs or demands until they are met. We can feel like no one is listening and necessary steps are being missed.

An other-oriented approach also means taking a step back to consider the bigger picture in terms of everyone's needs and goals. After doing so, it becomes easier to communicate effectively to make a plan that addresses the most pressing concerns first, while being mindful of secondary and tertiary steps. Even one person on a team who successfully enacts the other-oriented approach can help to calm the situation and help members reorient to focus on the conversation, task, or challenge at hand.

- Meaning-centered approach: Adopting a meaning-centered approach to communication involves mastering intentional language, active listening, and an other-oriented approach. A meaning-centered view is the most complex and the most impactful as it requires individuals to be accountable for the ways in which they communicate. This includes being responsible for sensitive language choices, verifying that they are interpreting others' messages as they are intended, and demonstrating patience and skill in 
navigating complex or challenging situations by hearing and addressing others' concerns before privileging their own.

Additionally, a meaning-centered approach can include attempting to hear what someone means rather than what they are saying and considering how a person may change their communication tendencies depending on the situation. For example, while a team member may be saying they agree with the prevailing opinion, but their arms are crossed and they are fidgeting in their seat, an individual enacting a meaning-centered approach to communication may say "While it sounds like we're in general agreement, is there another possible option or consequence that we have not yet considered?" This aligns with suggestions forwarded in Chapter 5, Interdisciplinary Palliative Care Team Meetings. In sum, a meaning-centered approach encourages team members to consider the following while collaborating to deliver patient-centered care:

-Members' unique roles

-Situational goals

-Time and resource constraints

-Using intentional communication to play to individual strengths

-Using intentional communication to fortify team relationships

In summary, viewing communication as foundational empowers providers to be responsible for not only what they communicate but also how they communicate in the workplace. This is even more important in interdisciplinary and transdisciplinary teams where varied occupational training experiences often lead clinicians to use different language, make different assumptions, and employ different approaches to problem-solving. Yet, by modeling foundational communication skills, providers are equipped to successfully navigate these differences while maintaining a focus on patient-centered care and their own goals and specific responsibilities. One palliative care physician found that in the five years since his PCT was established, some positive changes in communication and structural changes in paperwork are directly related to the work of his team:

I work with internal medicine residents and they have patterned their communication style with families after what we do on this team. And the family medicine residents truly see us as a part of their team now. I was just reviewing a bunch of order sets for oncology and noticed they redid their chemo order sets and now there is checkmark for a palliative care consult-so it is no longer just an afterthought or suggestion. Our patient census continues to go up as more people see value in it. When we started, everyone thought this one oncologist was going to be a big 
obstacle. He interacted okay with me but did not talk to the nurses or social workers on the core team. Not anymore. Now he interacts with them like they are best friends, and all I hear is praises.

Box 1.5 shows the foundational role of communication in action via a successful organizational change campaign to improve patient outcomes (Wick et al., 2015).

\section{BOX 1.5}

\section{FOUNDATIONAL ROLE OF COMMUNICATION IN ACTION}

What: Johns Hopkins Hospital utilized a trust-based accountability model to improve patient-centered outcomes, experience, and value in colorectal surgery (Wick et al., 2015).

Who: Organizational members of all levels and areas of expertise, from the chief financial officer and senior vice president for patient safety and quality to frontline care providers

How: A meaning-centered approach to communication was enacted via a trust-based accountability model. Instead of approaching change as most organizations do (a) from a top-down approach with mandates from senior leadership, (b) with frontline employees trying to make meaningful changes without the support of senior leadership, or (c) without assembling an interdisciplinary project team, Johns Hopkins valued the expertise of each unit and highlighted the need to work collaboratively across the organization. This included a focus on the following:

1. Individual and unit responsibility, role clarity, and feedback

2. Capacity of all members to model safety related to their individual role

3. Providing members with the required resources, including time, to successfully consider, pilot test, and integrate new organizational processes

Results: The integration of new processes resulted in decreased lengths of stay and patients reported increased satisfaction with staff responsiveness, communication about medication, and pain management (p. 675). Moreover, over $90 \%$ of patients suggested that they would recommend the hospital to family and friends, which was more than a $10 \%$ increase from previous years.

Meaning-Centered Approach: The example in Box 1.5 illustrates a communicatively complex way of organizing and facilitating change in the healthcare setting. Stakeholders at all levels of the organization were integrated in meaningful ways, 
where members were empowered to share their expert opinions as the process unfolded. This illustrates that the organization took an audience-centered approach in letting the relevant experts weigh-in and guide aspects of the process that aligned with their individual expertise. Relatedly, this approach also illustrates active listening across the workgroup as members had to listen to understand the recommendations made by each area and thoughtfully consider how they would impact the process as a whole. The authors note that tweaks were made throughout the process, which demonstrates flexing communicatively in order to align individual roles, goals, and areas of expertise across multiple disciplines for the benefit of patient care.

Embracing a meaning-making approach is particularly helpful in environments of intense emotional labor like palliative care. This intensity compounded by communication challenges can lead to feelings of helplessness and higher rates of provider burnout. Some studies show up to $62 \%$ of palliative providers burn out (Kamal et al., 2016), and this remains the highest burn out rate of all healthcare specialties. Mnemonics such as RENEW (Recognizing, Embracing, Nourishing, Embodying, and Weaving a New Response; Back, Rushton, Kaszniak, \& Halifax, 2015) focus on processes to deal with this emotional intensity in caring environments. Models such as this one are strengthened when used in context with constructive intrapersonal communication practices such as mindfulness and effective team communication. The COMFORT model by Wittenberg-Lyles, Goldsmith, Richardson, Hallett, and Clark (2011) focuses on the nursing position in palliative care through Communication, Orientation and opportunity, Mindful presence, Family, Openings, Relating, and Teams. The oft-used model for nursing does nod to the nested position of the nurse in a team. The focus of this text is on the $\mathbf{T}$-how to form and maintain healthy teams in palliative care. Exhibit 1.2 is an excerpt from a patient care coordination meeting (aka "rounds") where the team works to solve an issue for a patient.

The team in Exhibit 1.2 works well together for problem-solving. In this one situation, there are a number of factors that contribute to a problem that no one person is capable of solving on their own. It takes the team to understand and address each factor, including the following: the correct medication and its cost, the insurance issues, the nuances of a particular skilled nursing facility's admission practices, and the patient's social support system. The excerpt in Exhibit 1.2 is also an example of patient-centered care. This specific medication is what the patient needs, but the healthcare system is not built to easily help the patient. In less than 90 seconds, this team creates solution after solution. Most of the solutions have a flaw, and the team identifies that flaw and works out the next version of the solution. They arrive at a plan for how to solve this issue for this patient today that 


\section{EXHIBIT 1.2}

\section{MINI CASE STUDY: TEAM PROBLEM-SOLVING FOR A DIFFICULT DISCHARGE TO SKILLED NURSING FACILITY (SNF)}

\begin{tabular}{|c|c|}
\hline Dianne (APRN): & $\begin{array}{l}\text { So Lila. Lila was supposed to go out today, but Kathy got } \\
\text { a message from the doc that said they could not order a } \\
\text { different med-Lila had a repeat sensitivity on her urine that } \\
\text { was colonized; VRE was higher. So they're not okay with } \\
\text { switching her to a less expensive antibiotic. }\end{array}$ \\
\hline Kathy (PharmD): & Are the sensitivities back on that? On the second one? \\
\hline Dianne: & $\begin{array}{l}\text { Yeah, they are. She said the colonization was higher, and so } \\
\text { they felt like if they put her on anything besides linezolid, } \\
\text { she's not going to do well. }\end{array}$ \\
\hline Kathy: & $\begin{array}{l}\text { I did find out, though, that there is a program to help pay } \\
\text { for linezolid. I can get my hands on the coupon, and it } \\
\text { covers, like, } \$ 600 \ldots . . \text { the patient pays the first } \$ 15 \text {, and then } \\
\text { it covers the next } \$ 600 \text {. If they... she does have insurance, } \\
\text { right? }\end{array}$ \\
\hline $\begin{array}{l}\text { Miriam (Social } \\
\text { Worker): }\end{array}$ & $\begin{array}{l}\text { She does. Would we discharge her with that, then? Because } \\
\text { how would you facilitate the SNF getting the drug for her? }\end{array}$ \\
\hline Kathy: & Wait_if she goes to an SNF, do they not pay for her meds? \\
\hline Miriam: & They do, but ... they won't pay for the linezolid. \\
\hline Dianne: & $\begin{array}{l}\text { So if you [Miriam] do her packet and send it with the packet } \\
\text { and tell the SNF, "There's a coupon coming"- }\end{array}$ \\
\hline Kathy: & $\begin{array}{l}\text { I mean, that's what I want-I don't know the answer to that, } \\
\text { if they can't or won't fill it. }\end{array}$ \\
\hline Leslie (RN): & $\begin{array}{l}\text { So does she have family? Could it be filled by somebody at } \\
\text { a pharmacy, and then send it with the family? }\end{array}$ \\
\hline Miriam: & $\begin{array}{l}\text { It could be, but remember the admitting person at the SNF } \\
\text { can be a mean lady. }\end{array}$ \\
\hline Leslie: & Yeah, it would be difficult. \\
\hline Kathy: & Okay, what if it was filled through our pharmacy? \\
\hline Dianne: & That would work. \\
\hline Kathy: & Could we just send the bottle with her, then? \\
\hline
\end{tabular}




\begin{tabular}{|l|l|}
\hline Miriam: & $\begin{array}{l}\text { Yeah. I mean, the same way you would send a patient's own } \\
\text { medicine from here-yeah. I think that would work if it came } \\
\text { from here. }\end{array}$ \\
\hline Leslie: & Yeah. That would be optimal. \\
\hline Kathy: & $\begin{array}{l}\text { And then we'd need a script from the doctor and the doctor } \\
\text { to fill something out on this coupon form. I think we can get } \\
\text { it done today before the discharge. }\end{array}$ \\
\hline
\end{tabular}

matches the patient's need medically and financially while also circumventing some of the potential problems that occur when a patient is transferred from one facility to another. This interdisciplinary interaction exemplifies the importance of team-based palliative care. The team is efficient, collaborative, and creative in their problem-solving, and, most importantly, they achieve their goal of providing excellent care for this seriously ill patient.

\section{Ambiguity in Systems and Teams: A Primary Challenge for Palliative Care}

A primary reason palliative care communication is so challenging is due to the equivocal nature of the discipline. Equivocality is the degree to which a situation is ambiguous or given to more than one meaning. Working with patients and families with life-limiting and/or life-ending diagnoses introduces uncertainty at many levels.

- Many healthcare providers still view palliative care as a sign that patients or their healthcare providers have given up and failed. The road map for caring for a patient without an intent to cure is confusing if a provider feels that they have failed the patient.

- PCTs are constructed of numerous disciplines. While they may be united in their desire to care for patients and families at the end of life, their training and practices may be quite different and involve numerous unconscious defaults in perception and decision-making.

- A team of multiple disciplines is involved in the complex organization of a hospital, and that complex organization often must work with other complex organizations such as hospices that are not affiliated with the hospital, social welfare agencies, and insurance companies.

- Palliative care providers have difficulty finding people outside their workplace who understand their jobs. This limits their options for discussing work outside the small circle of their immediate colleagues. As one nurse 
shared, "Nobody else understands this kind of work ... You can't really talk to your family because they say 'That sounds really sad.' It's really not." Her pharmacist colleague agreed, saying that before she joined the PCT, "I thought our meetings would be sadder, dryer. They really aren't.'

All of these factors add up to a complex personal and familial health situation cared for by a complex group of people housed in a complex organization that interfaces with a complex system of organizations. Add emotional labor to all of that complexity (Figure 1.1) and it is no wonder that palliative programs are on the rise due to need while simultaneously suffering due to burnout.

Given the intensity and vital nature of the challenge to improve PCT functioning through better communication, Weick's (1995) Sensemaking in Organizations framework is a helpful guide. Weick explains that organizations, and the teams and groups of which they are made, are really verbs rather than static nouns. Organizations are always organizing and thus may be better understood as active bodies rather than fully formed and unchanging things. If we consider hospitals and PCTs in this light, the model of organizing better fits the day-to-day work as well as the attempt to evolve healthcare past the model of the separation of disciplines working in silos. Weick's work on high-reliability organizations (2005) fits healthcare systems perfectly. High-reliability organizations are those that operate in complex, high-hazard domains for extended periods without serious accidents or catastrophic failures (Agency for Healthcare Research and Quality, 2019). These organizations maintain an environment of mindfulness through the following actions: preoccupation with failure, reluctance to simplify, sensitivity to operations, deference to expertise, and commitment to resilience (Weick \& Sutcliffe, 2007).

Sutcliffe et al. (2004) talk about the latent flaws in the medical system that can lead to mishaps and oversights in patient care. These obstacles include complex and fragmented healthcare systems, faulty or nonexistent communication,

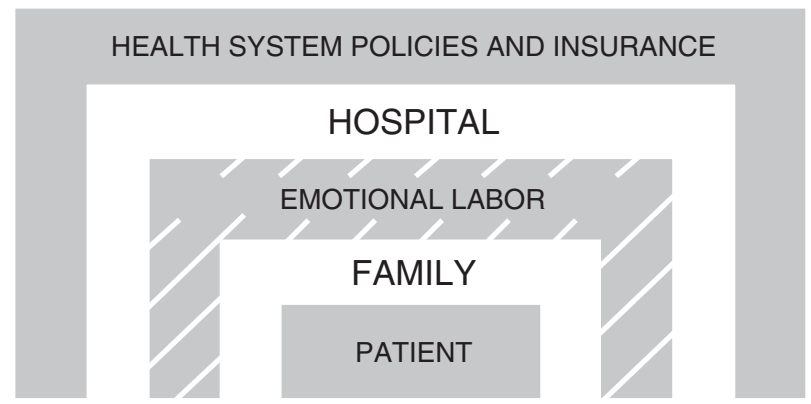

FIGURE 1.1 Emotional labor in palliative care. 
hierarchies and power differences, fear of upward influence, role conflict and ambiguity, interpersonal power struggles, and team conflict. As teams work to overcome these obstacles, the following urges may be strong: to focus only on the positive, oversimplify relationships, ignore the larger context in which the team is embedded, revert to hierarchical decision-making, and decide that if the system does not work, it is the fault of an individual person. All of these leanings go against Weick's advice. Take the problem-solving case in Exhibit 1.2. This minicase study shows team members working together in a somewhat ambiguous situation to discover a solution for a patient. They do not get angry when a member who is not in charge of prescribing has an idea, and they do not get frustrated when the initial ideas turn out to be unworkable. Their consistent engagement and focus on solving the problem results in a good solution for this patient.

\section{Palliative Care Training and Education}

As the need for palliative care remains strong, the number of palliative care fellowships and master's certificates continues to grow. While palliative specialists are needed, primary palliative education is also required to ensure that:

1. Patients have healthcare professionals who understand the need to offer a range of options including good pain management.

2. Physicians make referrals to PCTs when appropriate.

However, change comes slowly to all fields, and the 2014 IOM report notes that widespread adoption of timely referral to palliative care has been slow (IOM, 2014). While gains in clinical skills for seriously ill patient care are improving, understanding of palliative care is still deficient for many newly educated physicians. For example, a 2015 study of 176 hematology and oncology fellows found that $100 \%$ felt it was important to learn how to care for the dying, and, compared to an earlier survey, the number of fellows completing a palliative care rotation rose from $26 \%$ in 2005 to $44.9 \%$ in 2015 (Thomas et al., 2015). The study also found increasing competency in the following areas: pain management, informing patients of poor prognoses, and determining when to refer a patient to hospice. These increases in clinical skills are important for patient care. However, the study also found that " $25 \%$ of fellows reported no explicit teaching on key palliative care skills such as assessing prognosis, conducting a family meeting to discuss treatment options, and referral to palliative care" (p. 749). These data remind us that while medical education continues to add to the skill base and awareness of physicians, there remains a need for better preparation of providers to work together at the interdisciplinary level and do the complex and vital work of palliative care on PCTs. 
One way to approach this complex work is to reconsider how teams are constructed and their norms for working together. Across the professional practice of PCTs, conceptualizing teams as transdisciplinary rather than interdisciplinary points out a new way of functioning. In addition to drawing from multiple disciplines, transdisciplinarity "integrates natural, social and health sciences ... and transcends their traditional boundaries" (Choi \& Pak, 2006, p. 351). This text uses the term interdisciplinary. Although the use of transdisciplinary is gaining traction in organizations such as CAPC, it is not a widely used term at this time. For interdisciplinary and transdisciplinary teams, communication becomes even more vital for connecting and sharing information across disciplines. David Weissman, founding editor of the Journal of Palliative Medicine, notes that while ever-increasing demand for palliative care services and teams is good news, "the downside is that most teams I meet with are struggling, overwhelmed by work demands.... Faced with growing clinical demands, teams follow a predicable path, whereby they increase their clinical workload at the expense of data collection, education, quality improvement, and most importantly, team health" (2015, p. 204). Weissman finds that stressed teams tend to retreat to their silos and abandon even the appearance of relying on the other disciplines in their teams and thus violating "a foundational precept of palliative care" (2015, p. 204).

Weissman's observations concerning stressed teams retreating to silos is a process worthy of more study due to the growing reliance on teams in healthcare and particularly for PCTs. As hospitals and health systems move to form more PCTs to benefit patients and bottom lines, treating team formation as a simplistic process can easily backfire. Considerations such as professional identity, team identity, conflict styles, and organizational culture will all impact the success of a PCT.

An additional challenge for palliative care is that this care functions best as interdisciplinary teams, and that, too, is expertise in short supply. Healthcare providers often have interdisciplinary experience outside of a team-based workplace. For example, many clinicians in cancer care routinely work with social workers and chaplains as well as nurses and other healthcare providers (Eggly et al., 2009). Thus, while they have experience consulting other disciplines, they have less experiences thinking as a team and considering resources (human and budgetary) as a team. The ability to work competently in interdisciplinary settings goes beyond the ability to be a nice person with whom people like to work. Teams are complex, and PCTs must work in a context that is also complex on many levels including care of seriously ill patients and communication with patients and their families. These multilayered medical and interpersonal situations also take place in the complexity of hospital and health systems, which are affected by healthcare policy and financial concerns. 
One way to describe palliative care environments for information and relationships is the concept of equivocality. Equivocal environments have many information and relational inputs. As palliative care adds multiple layers of organizational decision-making in an ever-changing policy environment, a very complex system emerges. Karl Weick (1995) coined the term requisite variety to explain that complex organizations require problem-solving ability that matches that level of complexity. This way of thinking about meaning making and equivocality in organizations is not unlike a differential diagnosis. To reach a diagnosis, healthcare providers consider the numerous possibilities based on the symptoms. Those symptoms are considered in the context of the patient's history, age, and environment, among other factors, and the conclusion is drawn about the most likely cause of the symptoms. The symptoms and patient history and everything else considered for the patient are like the equivocality in teams. Given the many informational inputs, a PCT meets the requisite variety because it assembles the range of knowledge and practice needed for the patient on one team. As the problems to be solved in palliative care range from medication decisions to family conflict to department-based conflict, the team will work best when communicatively competent healthcare professionals are prepared to be nimble in thought and practice as they help seriously ill patients and their families.

Palliative care involves numerous moving parts, and therefore, simply assembling a team of people who fit the disciplinary requirements for the team is unlikely to result in the characteristics of high-performing PCTs noted in Table 1.1. A 2018 study of primary PCTs in the United Kingdom found that the 2011 Gold Standards Framework, a well-researched and presented guide of the care of endof-life patients and their families, fails to help teams perform better because while it tells them what to do, it does not help teams understand how to work together to achieve the stated goals (Hackett, Ziegler, Godfrey, Foy, \& Bennett, 2018). As one physician on a high-performing PCT wondered, "How did we build a team that's been this high-functioning and successful? Divine intervention?" His question indicates that while high-performing teams are the result of conscientious communication and attention to team development, the process for achieving high-performing status may be hard to recognize and perform. This text will assist teams and organizations in discovering the necessary elements to help them form and maintain high-performing PCTs.

Given the call to meet a growing need for palliative care, it is tempting to believe that simply creating more PCTs is the answer. However, such teams must also be visible and supported in their hospitals. Patients get to PCTs through referrals, and thus, PCTs must not only work to be a great team but also work with other clinicians to get referrals. A 2018 study on the growth of the subspecialty of 
pediatric palliative care teams (PPCTs) found that the most persuasive element to convince clinicians to provide referrals was educating non-PPCT clinicians that one call/referral to the PPCT meant that the referring clinician was spared coordinating large groups of professionals for the patient's case. The PPCT was already organized to coordinate that care in conjunction with the referring physician (Verberne et al., 2018). This discovery led to an increase in referrals, and that increase was amplified when referring physicians reported that the quality of the patient's care increased due to the involvement of the PPCT. In other words, good press begets more interest and referrals and shows that the investment in forming and maintaining a high-performing PCT will likely continue to grow through referrals as the good news of the team spreads through the hospital and healthcare systems.

\section{Conclusion}

This chapter started by examining three truths of palliative care. Each chapter in the rest of the book takes on one of the big topics in PCT communication: PCT membership, forming and maintaining high-performing teams, team leadership, team meetings, occupational culture, and avoiding burnout through good selfcare and the creation of a healthy team environment. Chapters include many reflections and experiences from those working in palliative care, and each chapter concludes with a few "Pearls From the Field" to guide your continued learning on developing and maintaining high-performing teams.

The need for PCTs will continue to grow. However, without a focus on intentional communication, team building, and relational maintenance, teams are likely to have high turnover rates. The high intensity of patient and family work in palliative care amplifies the stakes-if organizations and team leaders do not build a team that helps one another thrive through working together, the teams themselves become one more factor that adds to high burnout rates. This text is designed to provide workable solutions to challenges such as poor team design, siloing, and faulty communication. This focus allows groups of professions who are passionate about palliative care to grow into high-performing teams with a focus on patient care.

Ultimately, good palliative care is provided for patients and families through team-based care constructed from clinical expertise and skillful communication. When done well, PCTs do more than provide care and comfort for patients and families with serious illnesses. PCTs can offer emotional support, personal and occupational identity clarity, and organizational benefits to palliative care professionals. When the mission of the profession is to care for others in their time of great need, focus on building strong and sustainable PCTs is necessary. 


\section{PEARLS FROM THE FIELD: PROVIDER AND TEAM TAKEAWAYS}

Takeaway 1: Palliative care is important work and palliative care teams are an excellent way to accomplish patient and family care.

The vital work of palliative care can be exhausting - patients and families dealing with serious illness and complex healthcare systems have many needs, and those needs can wear on even the most practiced palliative care provider. Utilizing PCTs is an efficient and effective way to provide great care while capitalizing on the expertise of numerous specialties on a single team. Each PCT member learns from and can lean on other team members, as they help patients and families navigate healthcare systems, physical and emotional experiences, spiritual questions, and the logistics of care. Great teams help team members do more than survive the difficulties of such work; they help them to thrive.

Takeaway 2: Effective communication is intentional and can be time-consuming but can prevent medical mishaps and destructive team conflict.

Communication is the oft-cited but seldom explored centerpiece of communication between patients and providers, patients and families, providers and families, and providers with one another. Making the effort to learn to recognize effective communication is a worthwhile investment for providers and for PCTs. A strong, healthy team has the benefit of multiple perspectives. They also have sufficient trust to question one another for the well-being of the patient without throwing the team into destructive conflict every time a decision or order is questioned. A healthy team expects input from team members, and that input can save the team from making medical mistakes in the care of seriously ill patients.

\section{References}

Agency for Healthcare Research and Quality. (2019). Patient safety primer: High reliability. Retrieved from https://psnet.ahrq.gov/primers/primer/31/High-Reliability

Atayee, R., \& Edmonds, K. P. (2018). This is why we eat lunch together. Journal of Palliative Care, 21(10), 1386. doi:10.1098/jpm.2018.0274

Bachmann, C., Abramovitch, H., Barbu, C. G., Cavaco, A. M., Elorza, R. D., Haak, R., ... Rosenbaum, M. (2013). A European consensus on learning objectives for a core communication curriculum in health care professions. Patient Education and Counseling, 1, 18-26. doi:10.1016/j.pec.2012.10.016

Back, A. L., Rushton, C. H., Kaszniak, A. W., \& Halifax, J. S. (2015). "Why are we doing this?": Clinician helplessness in the face of suffering. Journal of Palliative Medicine, 18(1), 26-30. doi:10.1089/jpm.2014.0115

Billings, J. A. (2002). Vicissitudes of the clinician-patient relationship in end-of-life care: Recognizing the role for teams. Journal of Palliative Medicine, 5(2), 295-299. doi:10.1089/109662102753641296 
Candrian, C. (2015). The cost of care. Health Communication, 30, 732-736. doi:10.1080/1 0410236.2014.930771

Center to Advance Palliative Care. (2018). Serious illness quality alignment hub scorecard 2018. Retrieved from https://www.capc.org/payers-policymakers/quality-alignment-hub/

Center to Advance Palliative Care. (2019a). Making the case: Research in the field. Retrieved from https://registry.capc.org/metrics-resources/research-in-the-field/

Center to Advance Palliative Care. (2019b). Reaching the tipping point. Retrieved from https://tippingpointchallenge.capc.org/

Centers for Disease Control and Prevention. (2019). Chronic diseases in America. Retrieved from https://www.cdc.gov/chronicdisease/resources/infographic/chronic-diseases .htm

Choi, B. C., \& Pak, A. W. (2006). Multidisciplinarity, interdisciplinarity and transdisciplinarity in health research services, education and policy. Clinical Investigation Medicine, 29(6), 351-364.

Compton-Phillips, A., \& Mohta, N. S. (2019, June 6). Care redesign survey: The power of palliative care. NEJM Catalyst. Retrieved from https://catalyst.nejm.org/power-palliative -end-of-life-care-program/

Davis, M. P., Temel, J. S., Balboni, T., \& Glare, P. (2015). A review of the trials which examine early integration of outpatient and home palliative care for patients with serious illnesses. Annals of Palliative Medicine 4(3), 99-121. doi:10.3978/j.issn.22245820.2015.04.04

Dudley, N., Chapman, S., \& Spetz, J. (2018). Community-based palliative care leaders perspectives on staffing, recruitment, and training. Journal of Hospice \& Palliative Nursing, 20(2), 146-152. doi:10.1097/NJH.0000000000000419

Dumanovsky, T., Augustin, R., Rogers, M., Lettang, K., Meier, D. E., \& Morrison, R. S. (2016). The growth of palliative care in U.S. hospitals: A status report. Journal of Palliative Medicine, 19(1), 8-15. doi:10.1089/jpm.2015.0351

Eggly, S. S., Albrecht, T. L., Kelly, K., Prigerson, H. G., Kennedy Sheldon, L., \& Studts, J. (2009). The role of the clinician in cancer clinical communication. Journal of Health Communication, 14(Suppl. 1), 66-75. doi:10.1080/10810730902806778

Fulmer, T., Escobedo, M., Berman, A., Koren, M. J., Hernández, S., \& Hult, A. (2018). Physicians' views on advance care planning and end-of-life care conversations. Journal of the American Geriatrics Society, 66, 1201-1205. doi:10.1111/jgs.15374

Hackett, J., Ziegler, L., Godfrey, M., Foy, R., \& Bennett, M. I. (2018). Primary palliative care team perspectives on coordinating and managing people with advanced cancer in the community: A qualitative study. BMC Family Practice, 19, 177. doi:10.1186/s12875018-0861-Z

Hales, S., Zimmermann, C., \& Robin G. (2010). Review: The quality of dying and death: A systematic review of measures. Palliative Medicine, 24(2), 127-144. doi:10.1177/ 0269216309351783

Imes, R. S., \& Hester, J. (2015). Unintended intentional community at work: Applying a new lens to guide the formation and maintenance of transdisciplinary teams. Paper presented at the National Communication Association Annual Convention, Las Vegas.

Institute of Medicine. (2014). Dying in America: Improving quality and honoring preferences near the end of life. National Academy of Sciences. Retrieved from http://www .nationalacademies.org/hmd/Reports/2014/Dying-In-America-Improving -Quality-and-Honoring-Individual-Preferences-Near-the-End-of-Life.aspx

Jennings, T. (Producer). (2015). Being mortal [series episode). Frontline. Boston, MA: PBS Broadcasting. 
Kamal, A., Bull, J., Swetz, K., Wolf, S., Shanafelt, T., \& Myers, E. (2017). Future of the palliative care workforce: A preview to an impending crisis. The American Journal of Medicine, $130(2), 113-114$.

Kamal, A. H., Bull, J. H., Wolf, M. S., Swetz, K. M., Shanafelt, T. D., \& Abernathty, A. P. (2016). Prevalence and predictors of burnout among hospice and palliative care clinicians in the U.S. Journal of Pain and Symptom Management, 51(4), 690-696. doi:10.1016/j.jpainsymman.2015.10.020

Kavalieratos, D., Corbelli, J., Zhang, D., Dionne-Odom, J. N., Ernecoff, N. C., Hanmer, J., ... Schenker, Y. (2016). Association between palliative care and patient and caregiver outcomes: A systematic review and meta-analysis. JAMA, 316(20), 2104-2114. doi:10.1001/ jama.2016.16840

Kerr, C. W., Tangeman, J. C., Rudra, C. B, Grant, P. C., Luckiewicz, D. L., Mylotte, K. M., ... Serehali, A. M. (2014). Clinical impact of a home-based palliative care program: A hospice-private payer partnership. Journal of Pain and Symptom Management, 48(5), 883-892. doi:10.1016/j.jpainsymman.2014.02.003

Klarare, A., Hagelin, C. L., Fürst, C. J., \& Fossum, B. (2013). Team interactions in specialized palliative care teams: A qualitative study. Journal of Palliative Medicine, 16(9), 1062-1069. doi:10.1089/jpm.2012.0622

Kousaie, K., \& van Gunten, C. F. (2017). Models of palliative care team composition: Nurse practitioner-only versus interdisciplinary teams that include specialist physicians. Journal of Palliative Medicine, 20(12), 1313. doi:10.1089/jpm.2017.0380

Ledford, C., Canzona, M., Cafferty, L., \& Kalish, V. (2016). Negotiating the equivocality of palliative care: A grounded theory of team communicative processes in inpatient medicine. Health Communication, 31(5), 1-8. doi:10.1080/10410236.2014.974134

Lingard, L., Whyte, S., \& Regehr, G. (2009). Safer surgery: Analysing behaviour in the operating theatre. Surrey, UK: Ashgate Publishing.

Makary, M. A., \& Daniel, M. (2016). Medical error-The third leading cause of death in the US. BMJ, 353, i2139.

May, P., Garrido, M. M., Cassel, J. B., Kelley, A. S., Meier, D. E., Normand, C., ... Morrison, R. S. (2017). Cost analysis of a prospective multi-site cohort study of palliative care consultation teams for adults with advanced cancer: Where do cost-savings come from? Palliative Medicine, 31(4), 378-386. doi:10.1177/0269216317690098

May, P., Normand, C., Cassell, J. B., Del Fabbro, E., Fine, R. L., Menz, R., ... Morrison, R. S. (2018). Economics of palliative care for hospitalized adults with serious illness: A meta-analysis. JAMA Internal Medicine, 178(6), 820-829. doi:10.1001/jamainternmed.2018.0750

McCarthy, I. M., Robinson, C., Huq, S., Philastre, M., \& Fine, R. L. (2015). Cost savings from palliative care teams and guidance for a financially viable palliative care program. Health Services Research, 50(1), 217-236. doi:10.1111/1475-6773.12203

Meier, D. (2019). “The Future of Palliative Care: A Podcast with Diane Meier" GeriPal - A Geriatrics and Palliative Care Podcast. Retrieved from https://www.geripal.org/p/geripal-podcast.html

Meier, D. E., Back, A. L., Berman, A., Block, S. D., Corrigan, J. M., \& Morrison, R. S. (2017). A national strategy for palliative care. Health Affairs, 26(7), 1265-1273. doi:10.1377/ hlthaff.2017.0164

National Consensus Project. (2018). Clinical practice guidelines for quality palliative care (4th ed.). Richmond, VA: National Coalition for Hospice and Palliative Care. Retrieved from https://www.nationalcoalitionhpc.org/ncp

National Palliative Care Registry. (2017). Metrics and resources. Retrieved from https:// registry.capc.org/metrics-resources/ 
Nussbaum, J. F., \& Fisher, C. L. (2009). A communication model for the competent delivery of geriatric medicine. Journal of Language and Social Psychology, 28(2), 190-208. doi:10.1177/0261927X08330609

Omilion-Hodges, L. M., \& Baker, C. R. (2017). Communicating leader-member relationship quality: The development of leader communication exchange scales to measure relationship building and maintenance through the exchange of communication-based goods. International Journal of Business Communication, 54(2), 115-145. doi:10.1177/ 2329488416687052

Parker, J. (2019, April 4). Palliative care could cut health care costs by \$103B. Hospice News. Retrieved from https://hospicenews.com/2019/04/04/palliative-care-could-cut-health -care-costs-by-103-billion/

Quill, T. E., \& Abernathy, A. P. (2013). Generalist plus specialist palliative care--Creating a more sustainable model. The New England Journal of Medicine, 368(13), 1173-1175. doi:10.1056/NEJMp1215620

Scharf, B. F., Geist Martin, P., Cosgriff-Hernandez, K.-K., \& Moore, J. (2012). Trailblazing healthcare: Institutionalizing and integrating complementary medicine. Patient Education and Counseling 89, 434-438. doi:10.1016/j.pec.2012.03.006

Smith, T. J., Temin, S., Alesi, E. R., Abernethy, A. P., Balboni, T. A., Basch, E. M., . . Von Roenn, J. H. (2012). American Society of Clinical Oncology provisional clinical opinion: The integration of palliative care into standard oncology care. Journal of Clinical Oncology, 30(8), 880-7. doi:10.1200/JCO.2011.38.5161

Spetz, J., Dudly, N., Trupin, L., Rogers, M., Meier, D. E., \& Dumanovsky, T. (2016). Few hospital palliative care programs meet national staffing recommendations. Health Affairs, 35(9), 1690-1697. doi:10.1377/hlthaff.2016.0113

Sutcliffe, K. M., Lewton, E., \& Rosenthal, M. M. (2004). Communication failures: An insidious contributor to medical mishaps. Academic Medicine, 79(2), 186-194. doi:10.1097/ 00001888-200402000-00019

Thomas, R. A., Curley, B., Wen, S., Zhang, J., Abrahman, J., \& Moss, A. H. (2015). Palliative care training during fellowship: A national survey of U.S. Hematology and Oncology Fellows. Journal of Palliative Medicine, 18(9), 747-751. doi:10.1089/jpm.2015.0035

Verberne, L. M., Kars, M. C., Schepers, S. A., Schouten-van Meeteren, A. Y. N., Grootenhuis, M. A., \& van Delden, J. J. M. (2018). Barriers and facilitators to the implementation of a paediatric palliative care team. BMC Palliative Care, 17(1), 23. doi:10.1186/s12904018-0274-8

Watson, B. M., Heatley, M. L., Gallois, C., \& Kruske, S. (2016). The importance of effective communication in interprofessional practice: Perspectives of maternity clinicians. Health Communication, 31(4), 400-407. doi:10.1080/10410236.2014.9609222

Weick, K. (1995). Sensemaking in organizations. Thousand Oaks, CA: Sage.

Weick, K. (2005). Managing the unexpected: Complexity as distributed sensemaking. In R. R. McDaniel \& D. J. Dreibe (Eds.), Uncertain and surprise in complex systems: Question on working with the unexpected (pp. 51-78). Berlin: Springer-Verlag.

Weick, K. E., \& Sutcliffe, K. M. (2007). Managing the unexpected: Resilient performance in an age of uncertainty. San Francisco, CA: Jossey-Bass.

Weissman, D. E. (2015). Improving care during a time of crisis: The evolving role of specialty palliative care teams. Journal of Palliative Medicine, 18(3), 204-207. doi:10.1089/ jpm.2015.1014

Wick, E. C., Galante, D. J., Hobson, D. B., Benson, A. R., Lee, K. H. K., ...Wu, C. L. (2015). Organizational culture changes result in improvement in patient-centered outcomes: 
Implementation of an integrated recovery pathway for surgical patients. Journal of the American College of Surgeons, 221(3), 669-677. doi:10.1016/j.jamcollsurg.2015.05.008

Wittenberg-Lyles, E., Goldsmith, J., Richardson, B., Hallett, J. S., \& Clark, R. (2012). The practical nurse: A case for COMFORT communication training. American Journal of Hospital and Palliative Medicine, 30(2), 162-166. doi:10.1177/1049909112446848

World Health Organization. (2017). WHO definition of palliative care. Retrieved from http://www.who.int/cancer/palliative/definition/en/ 